\title{
Bogusława BERNER
}

\section{LATAJACE SAMOCHODY}

DOI: $10.24136 /$ atest.2018.278

Data zgłoszenia: 30.08.2018. Data akceptacji: 25.09.2018.

$W$ artykule przedstawiono historię poczatków produkcji latajacych samochodów. Opisano współczesne wyzwania stojace przed konstruktorami latajacych samolotów. Zaprezentowano firmy zajmujace sie konstruowaniem oraz produkcja latajacych samochodów. Przedstawiono niektóre z trwajacych prac nad projektowaniem oraz omówione zostały przyszłe strategie ich rozwoju

\section{WSTĘP}

Wzrastająca liczba pojazdów samochodowych, to rosnące utrudnienia w komunikacji miejskiej. W 2015 roku liczba samochodów na świecie wynosiła 1,1 mld, co oznacza, że na jedno auto przypadało 6,5 mieszkańca. W 2025 roku będzie to $1,5 \mathrm{mld}$, a 15 lat później już $2 \mathrm{mld}$. Stany Zjednoczone, posiadaja $320 \mathrm{mln}$ mieszkańców, którzy są w posiadaniu 265 mln samochodów, daje to 0,83 auta na osobę. W Polsce na 1000 mieszkańców przypada 599 aut, czyli o 35 więcej niż wynosi europejska średnia. Polacy w liczbie samochodów na mieszkańca wyprzedzaja m.in. takie kraje jak Francja, Hiszpania i Szwajcaria. Jeśli chodzi o przyrost liczby samochodów, przyszłość nie należy jednak do Europy. Prym będa wieść kraje rozwijające się, głównie Chiny i Indie [9]. Istniejący system komercyjnych linii lotniczych oraz masowych lotnisk również jest przeciążony. Większość podróży lotniczych odbywa się w głównych portach lotniczych kraju. Prowadzi to do zatorów w ruchu lotniczym, pomimo dużej nieużywanej przestrzeni na niebie pomiędzy korytarzami powietrznymi. Ostatecznie przyczynia się to do kosztownych oraz niewygodnych opóźnień w podróżach samolotem.

Latający "samochód", "drogowy samolot", "dwusystemowy pojazd" i inne terminy są używane do opisania uniwersalnego pojazdu, który może latać jak samolot i jechać po drodze jak samochód. Od dawna marzeniem entuzjastów lotnictwa oraz motoryzacji jest posiadanie pojazdu, który będzie posiadał te dwie funkcje. Konstruktorzy latajacych samochodów napotkają niestety na wiele przeszkód, w tym sprzeczne przepisy dotyczące samolotów i samochodów. Jako samochód taki pojazd musi być w stanie zmieścić się na szerokości pasa ruchu i mieć możliwość przejazdu pod drogowymi wiaduktami. W ruchu drogowy powinien dorównać typowym samochodom oraz spełniać wszystkie przepisy bezpieczeństwa, a także normy emisji spalin. Skrzydła oraz ogon takiego pojazdu powinny być chowane, aby dostosować pojazd do kształtu oraz wielkości typowych samochodów poruszających się po drogach. Kluczowym elementem w rozwoju udanego latającego samochodu jest zaprojektowanie systemu kontroli, który umożliwi kierowcy, a zarazem pilotowi obsługę pojazdu w dowolnym trybie podróży. System ten zapewni kontrolę lotu, nawigację oraz poprawi środowisko komunikacyjne. Zarówno latajacy samochód, jak i koncepcje drogowych samolotów zwykle zakładaja samodzielny system, zdolny do prostej ręcznej, a nawet automatycznej konwersji między trybem samochodu i samolotu.

\section{HISTORIA LATAJĄCYCH SAMOCHODÓW}

W 1917 roku Glenn Curtiss, którego można nazwać ojcem latającego samochodu, odsłonił pierwszą próbę takiego pojazdu. Jego aluminiowy Autoplan był trójpłatem, posiadał trzy skrzydła o długości 12,2 metra oraz śmigło z czterema łopatami zamontowane z tyłu pojazdu. Silnik o mocy 100KM napędzał tylnie śmigło za pomocą wału i pasów. W zamkniętej kabinie znajdowały się trzy siedzenia, z przodu dla pilota-kierowcy oraz dwa tylnie siedzenia dla pasażerów (Rys.1).

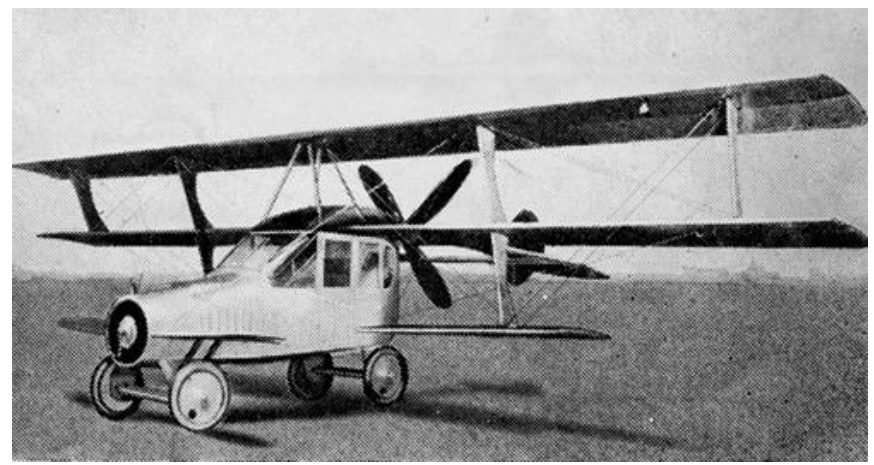

Rys. 1. Autoplane [22]

Autoplan posiadał czterokołowe podwozie, przednie dwa koła były sterowalne. W celu używania pojazdu jako samochodu można było odłączyć skrzydła oraz ogon. Chociaż pojazd był w stanie podnieść się z ziemi, nigdy nie osiagnał pełnego lotu.

Waldo Waterman w 1937 roku, opracował Arrowbile, trójkołowy latający samochód napędzany był typowym silnikiem o mocy 100 KM. Pojazd był dwuosobowy, sterowany zarówno na drodze, jak i w powietrzu za pomoca typowej samochodowej kierownicy.

Skrzydła jego były odłączane w momencie kiedy pojazd miał stać się samochodem, posiadał również tak jak typowe samoloty śmigło przyczepione z tyłu pojazdu (Rys. 2).

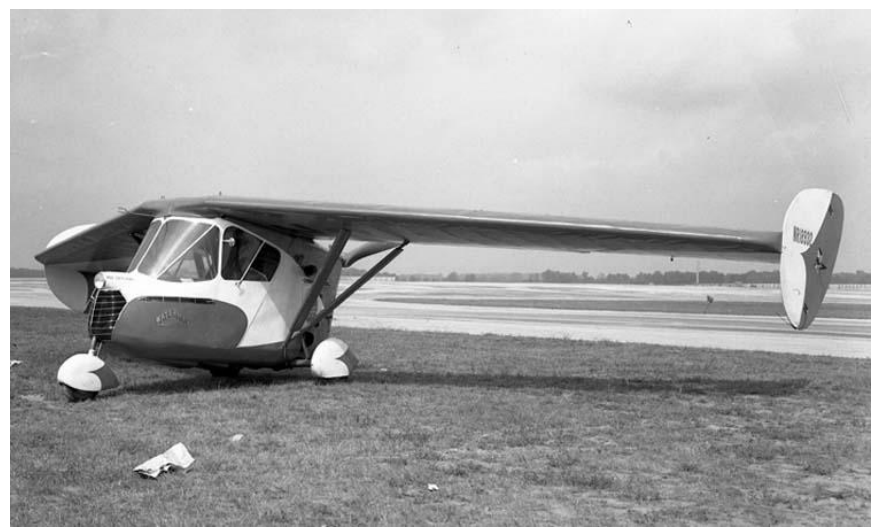

Rys. 2. Arrowbile [21] 


\section{Bezpieczeństwo i ekologia}

Robert Fulton, opracował Airfibian w 1946 roku. Przyjał on w projektowaniu konstrukcji pojazdu podejście polegające na przekształceniu samolotu w samochód za pomoca procesu konwersji. Skrzydła i część tylną samolotu można było usunać w celu przekształcenia go w samochód, śmigło Airfibian można było przechowywać we wewnatrzu kadłuba samochodu. Przejście samolotu na samochód zajmowała tylko pięć minut (Rys.3). Cała konstrukcja pojazdu była aluminiowa.

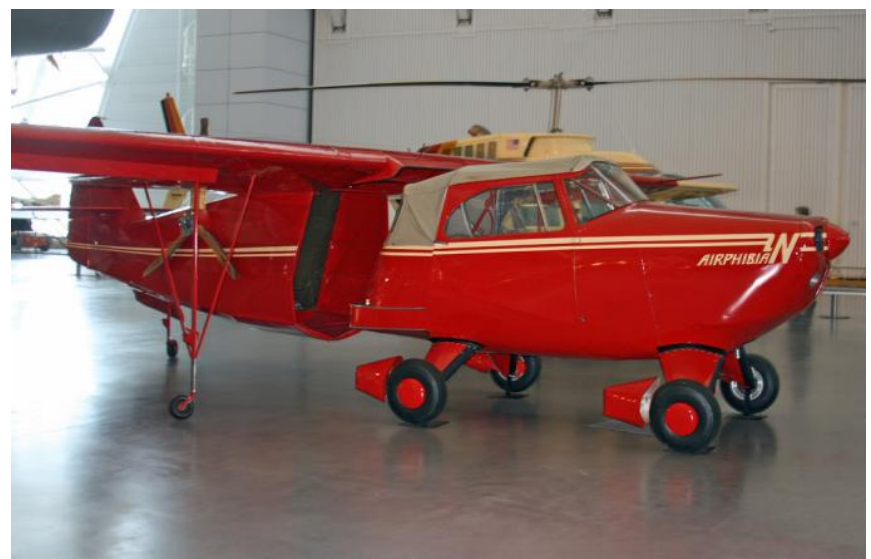

Rys. 3. Airphibian [20]

Airfibian był pierwszym latającym samochodem, który uzyskał certyfikat od Civil Aeronautics Administration, poprzednika Federalnej Administracji Lotnictwa (FAA). Pojazd posiadał sześciocylindrowy silnik o mocy $150 \mathrm{KM}$, w powietrzu rozwijał prędkość do 190 km/godz na drogach mógł jechać z prędkością $80 \mathrm{~km} / \mathrm{godz}$.

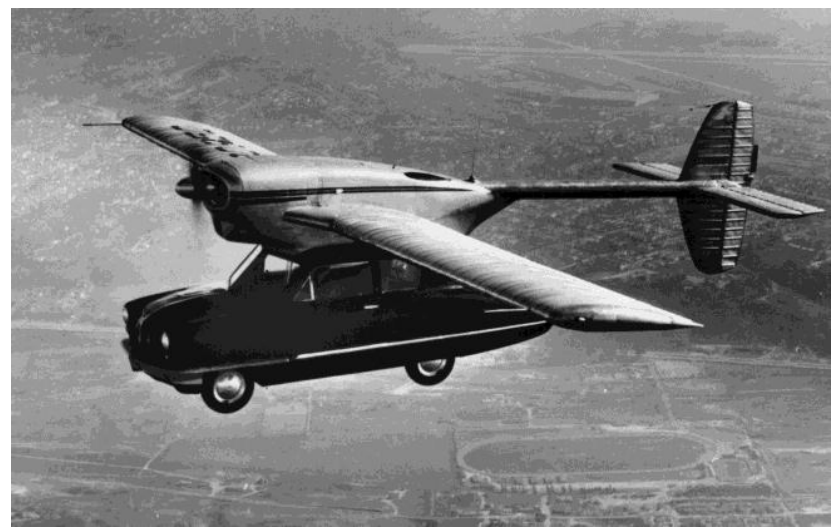

Rys. 4. Convair 118 [21]

Pod koniec lat 40. XX wieku został zaprojektowany przez Theodora Halla Convair 118, był to dwudrzwiowy sedan (Rys.4) wyposażony w odłączany samolot. Convair 118 zadebiutował w 1947 roku. Plany wprowadzenia pojazdu do sprzedaży niestety zakończyły się fiaskiem, gdy pojazd rozbił się podczas trzeciego lotu .Convair I 118 był czteroosobowym samochodem z nadwoziem zbudowanym z włókna szklanego. Samochód napędzany był silnikiem o mocy 26KM

\section{PRZEGLAD WYBRANYCH MODELI}

PAL-V Liberty, AeroMobil, Skycar 400, Terrafugia TF-X, oraz Pop.Up to nazwy niektórych modeli latających samochodów które, znajduja się obecnie w produkcji. Volkswagen, Toyota to uznane firmy motoryzacyjne, które również pracuja nad koncepcją latajacych samochodów. Nazwa PAL-V Liberty jest skrótem od Personal Air and Land Vehicle, co oznacza w tłumaczeniu na język polski, osobisty pojazd powietrzny i ladowy. Duńczycy pracowali nad swoim nietypowym projektem od 2001 roku. W marcu 2012 roku w powietrze wzbił się jego pierwszy prototyp. Jest to samochód i wiatrakowiec jednocześnie zdolny do przekształcania się z samochodu w wiropłat w około 5-10 minut (Rys.5). Maszt składa i rozkłada się automatycznie. Kierowca-pilot musi tylko wyciagnąc ręcznie ogon i rozłożyć łopaty wirnika. Pojazd nie startuje jednak pionowo musi mieć rozbieg [4].

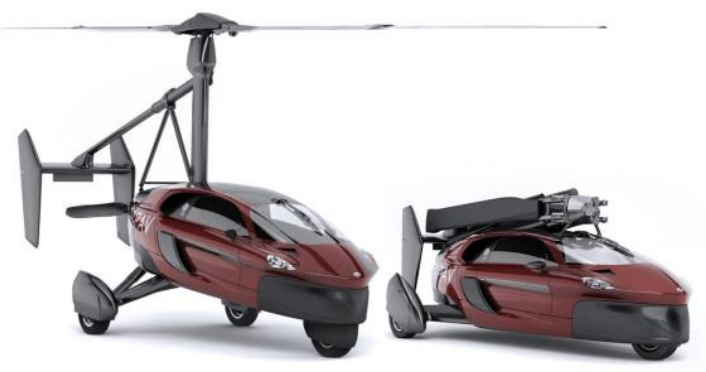

Rys. 5. PAL-V Liberty [15].

PAL-V Liberty ma być jednak stabilniejszy niż zwykły śmigłowiec, a przy okazji bardziej kompaktowy niż samolot ze stałym skrzydłem. Może być pilotowany w Europie z licencja pilota rekreacyjnego lub licencja pilotów prywatnych, a prawo jazdy to wszystko, czego potrzeba, aby prowadzić PAL-V Liberty na drogach. Podczas lotu, PAL-V Liberty może wzbić się na maksymalną wysokość $3500 \mathrm{~m}$.

Pojazd rozpędza się do $160 \mathrm{~km} / \mathrm{h}$ w trybie jazdy i do $180 \mathrm{~km} / \mathrm{h} w$ trybie lotu. Silnik posiada $100 \mathrm{KM}$, Zużycie paliwa na $100 \mathrm{~km}$ to 7,6 litra. Aby PAL-V Liberty mógł wzbić się w powietrze przy pełnym obciążeniu, potrzebuje pasa startowego o długości co najmniej 330 metrów. Maksymalna wysokość, na którą będzie można się wznieść, to 3,5 tys. metrów. Model ma być dopuszczony do ruchu na terenie Europy i USA, a klienci zainteresowani kupnem moga skorzystać z fabrycznych kursów poruszania się maszyną. Cena podstawowej wersji tego modelu to koszt około 400 tys. dolarów, ale wariant $z$ bardziej luksusowym wyposażeniem kosztuje już ponad 600 tys. dolarów. Dostawy pierwszych modeli do klientów indywidualnych rozpoczną się pod koniec 2018 roku [5].

AeroMobil Flying Car to nazwa dwumiejscowego latającego samochodu, który posiada rozsuwane skrzydła, dzięki nim pojazd gotowy jest do lotu w 3 minuty. AeroMobil Flying Car napędzany jest za pomocą dwulitrowego silnika benzynowego, który współpracuje z silnikiem elektrycznym, napędza on podczas jazdy przednie koła pojazdu posiada moc 300 KM (Rys.6.). Dzięki 90-litrowemu zbiornikowi paliwa pojazd może przejechać około $700 \mathrm{~km}$. W powietrzu zasięg zwiększa się do $750 \mathrm{~km}$, na ziemi pojazd rozpędza się do prędkości $160 \mathrm{~km} / g o d z$. W powietrzu okazuje się jednak znacznie szybszy. Prędkość przelotowa wynosi 259 km/godz. [1].

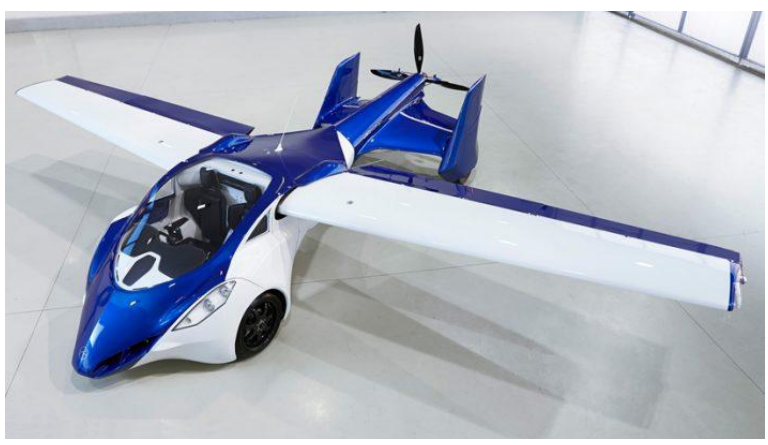

Rys. 6. AeroMobil Flying Car [16]. 
AeroMobil Flying Car może zabrać na pokład tylko dwoje ludzi oraz podręczny ładunek. Całość obciążenia pojazdu nie może jednak ważyć więcej niż $240 \mathrm{~kg}$. Potrzebny jest również pas startowy, którego minimalna długość to 397 metrów. Wysokość przelotu - 15 metrów, zapewnia bezpieczne pokonanie zabudowy miast. Użytkownik Flying Cara musi być posiadaczem prawa jazdy oraz licencj pilota. AeroMobil Flying Car ma kosztować 1,2-1,5 miliona euro. Dostawy do klientów mają się rozpocząć w 2020 roku. W pierwszej fazie zaplanowano produkcje 500 sztuk [2].

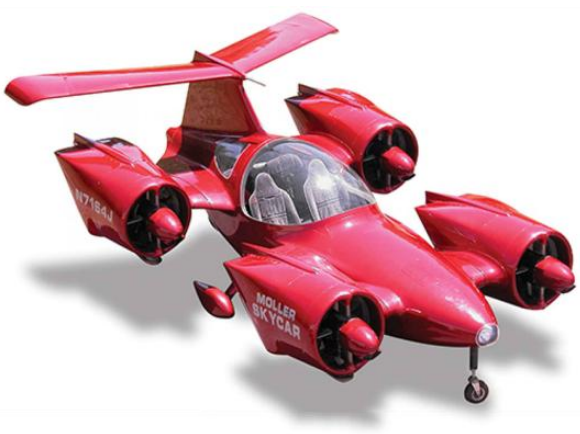

Rys. 7. Skycar 400 [13].

Skycar 400 to latający samochód opracowany przez dr Paula Mollera, obecnie znajduje się na etapie prototypu operacyjnego. Napędzany jest za pomocą ośmiu ekologicznych silników Wankla. Na wyposażeniu pojazdu znajduje się również spadochron, który używany jest w razie jego awarii pojazd pokazany jest na (Rys.7.) [7]. Paliwem napędowym pojazdu Skycar 400 jest etanol. Maksymalne osiagi Skycar 400: czas lotu pojazdu to 5,9 godz., pułap lotu $3 \mathrm{~km}$., prędkość to $500 \mathrm{~km} / \mathrm{godz}$. Na drogach porusza sie jedynie na krótkich dystansach [3].

Terrafugia TF-X to pierwszy w pełni autonomiczny samochód latajacy zaprojektowany przez bostońską firmę Terrafugię w Stanach Zjednoczonych. Projekt ten jest dopiero w fazie wstępnych przygotowań. Terrafugia TF-X posiada możliwość przewozu 4 osób. Pojazd zdolny jest do pionowego startu i ladowania (Rys.8.). Małe rozmiary samochodu pozwalaja na możliwość parkowania jego w garażu [3].
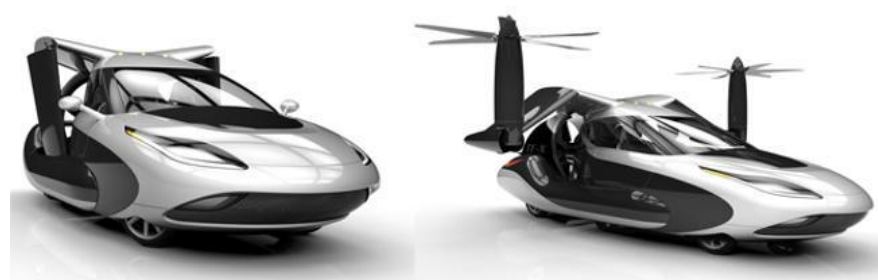

Rys. 8. Terrafuga TF-X [2].

Zasilany dwoma hybrydowymi silnikami elektrycznymi o mocy 600 KM oraz o mocy $300 \mathrm{KM}$, model TF-X ma mieć zasięg $805 \mathrm{~km}$ oraz rozwijać prędkościa przelotowa $322 \mathrm{~km} / \mathrm{h}$ [10]. W razie awarii, Terrafuga TF-X automatycznie wyląduje na najbliższym lotnisku. Pojazd posiada również spadochron na wyposażeniu, który można aktywować, jeśli operator uzna, że nie jest w stanie samoczynnie wylądować [11]. Terrafuga TF-X nie potrzebuje lotniska do startu, będzie mógł wystartować i wylądować pionowo z obszaru o powierzchni 30 metrów kwadratowych. Paliwo silnikowe będzie stanowić benzyna samochodowa bezołowiowa. Czas szkolenia na posiadanie licencji prowadzenia Terrafuga TF-X będzie znacznie krótszy niż czas potrzebny na szkolenia pilota tradycyjnego samolotu. Na- tomiast jazda w ruchu drogowym będzie wymagać jedynie posiadania prawa jazdy [12].

Firma Airbus ma inny pomysł na połączenie możliwości jazdy oraz latania. Razem ze studiem Italdesign stworzyli projekt latającego samochodu. Pop.Up to modułowy pojazd, który składa się z trzech elementów - kapsuły, układu jezdnego z kołami oraz modułu umożliwiającego lot (Rys. 9.).

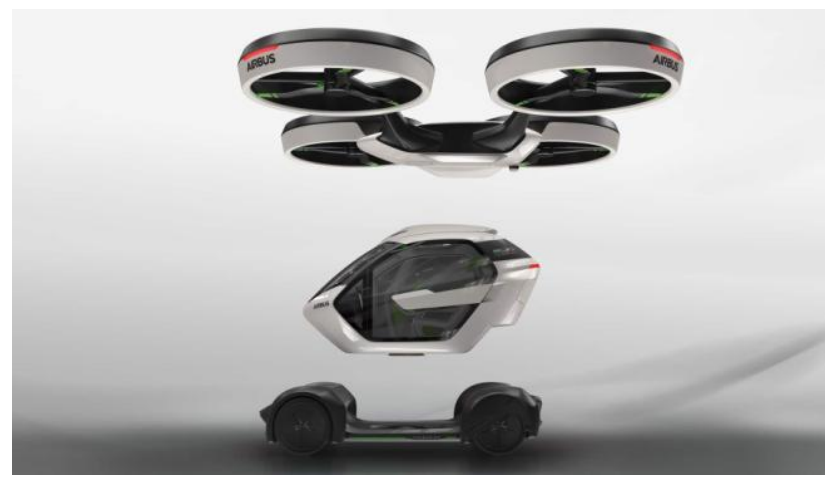

Rys. 9. Pop.Up [14].

Kapsuła pasażerska może być przytwierdzona do podwozia, dzięki czemu pojazd może normalnie jeździć po drogach jako miejskie auto, lub może być dołączony do kapsuły zestaw śmigieł który umożliwi jego lot [8]. Pop. Up jest pojazdem elektrycznym. Kapsuła pasażerska czerpie energię z akumulatorów które znajdują się w modułach Pop.Up.

Cały system ruchu Pop.Up ma być sterowany przez system informatyczny analizujacy ruch na drogach, torach i w powietrzu. Pasażer ma tylko wybrać w programie trasę, a system dobierze sugerowany sposób jej pokonania. W zależności od odległości, warunków i ruchu, trasa może być pokonana na ziemi lub w powietrzu.

Projekt Airbusa bardzo mocno wpisuje się w trend sharing economy, czyli ekonomia współdzielenia. Koncepcja przeciwna konsumpcjonizmowi. Zakłada dzielenie się, pożyczanie oraz wymianę produktów i usług. Zamiast prywatnego pojazdu, mamy pojazd wspólny, który możemy wykorzystywać wtedy, gdy faktycznie go potrzebujemy. Kiedy dojedziemy do pracy, pojazd nie musi stać bezczynnie na parkingu, a zamiast tego może służyć aktywnie komuś innemu.

Zee.Aero, to projekt latajacego samochodu, który zakłada możliwość startu oraz lądowania w pionie. Projektem tego pojazdu kieruje llan Kroo, profesor aeronautyki oraz naukowiec z NASA, który założył firmę Zee.Aero.

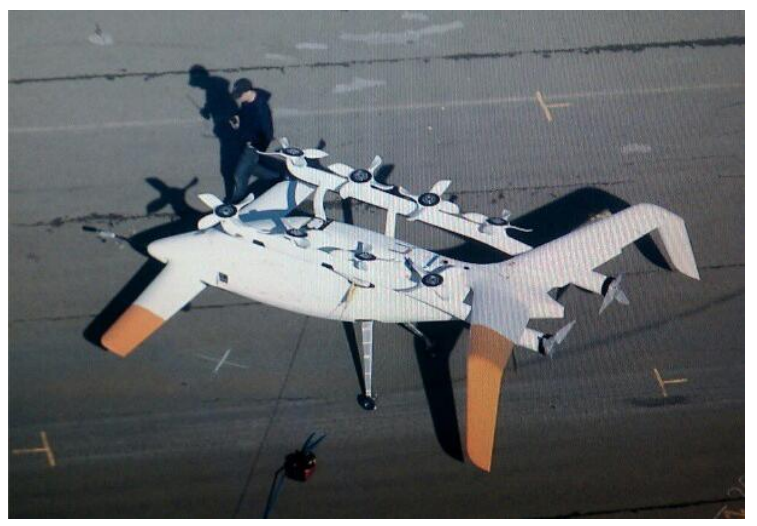

Rys. 10. Zee.Areo [18] 
W konstrukcji Zee.Aero możemy wyróżnić dwa skrzydła, które zamontowane są na dziobie oraz rufie pojazdu (Rys.10). Prócz tego pojazd posiada osiem silników elektrycznych, które znajdują się po cztery z każdej strony na bokach pojazdu. Silniki obracaja podwójne śmigła, uruchamiane są one w momencie startu Zee.Aero, w późniejszym etapie napęd przechodzi na dwa pionowe silniki które znajdą się na rufie pojazdu. Duża liczba silników zapewnia bezpieczeństwo w przypadku awarii, któregoś z nich Zee.Areo jest w stanie bezpiecznie wyladować. Sterowanie lotem w zawisie odbywa się poprzez zmianę ciagu silników. Pojazd jest napędzany ze wspólnego banku baterii lub generatora napędzanego benzyna. Sterowanie takim pojazdem jest bardzo proste z mechanicznego punktu widzenia, ale będzie wymagało skomplikowanego oprogramowania, aby samolot mógł latać. Całość konstrukcji Zee. Areo ma być zbudowana z włókna węglowego. Pojazd wymiarowo jest wystarczająco waski, aby zmieścić się w standardowym parkingu centrum handlowego [19].

\section{PODSUMOWANIE}

Wyzwania stojące przed inżynieryjnym projektowaniem osobistego latajacego samochodu są ogromne. Prowadzenie pojazdu wymaga certyfikatu pilota, a także wstępnego przeszkolenia wraz z prawem jazdy. Wiele modeli wymaga pozbawionego przeszkód pasa startowego. Niektóre modele latających samochodów zdolne do pionowego startu, jeszcze bardziej skomplikowałyby normy bezpieczeństwa ruchu i zasadniczo doprowadziłoby to do chaosu oraz poważnego zagrożenia w ruchu drogowym. Pojazdy te wymagają również intensywnej konserwacji, aby pozostały w idealnym stanie technicznym [17]. Zmienią one fundamentalnie sposób komunikacji. Lądowiska dla latających samochodów mogłyby znaleźć się na prywatnych budynkach lub na dachach centrów handlowych. Ludzie będą mogli mieszkać dalej od miast, w których pracuja oraz korzystać z osobistego latającego samochodu, by polecieć nim do wybranego miejsca.

\section{BIBLIOGRAFIA}

1. Blain L. AeroMobil Flying Car now available for pre-order April 27th, 2017. www.newatlas.com

2. Burns A. The luxurious AeroMobil Flying Car will begin shipping in 2020. Flying Subscribe April 21, 2017 www.flyingmag.com

3. Burns A. The Moller M400 Skycar is for Sale on eBay Flying Subscribe July 14, 2017. www.flyingmag.com

4. CarAndBike Team. Pal-V Liberty Flying Car Makes Its Public Debut 07, 2018 March Geneva 2018.www. auto.ndtv.com

5. Carriere D. February PAL-V Flying Cars Now for Sale. Dutch developer expects to make first deliveries by the end of 2018. www.flyingmag.com
6. Hawkins J. A You can now buy the Moller Skycar, one of the world's most iconic 'flying cars' 'It cannot be flown' The Verge Jul 6, 2017. www.theverge.com

7. Kautonen A. Pop.Up Next flying taxi concept. The flying pod gains better styling inside and out while shedding weight. Audi influences Geneva March 6th 2018. www.autoblog.com

8. O'Hare R. and Zolfagharifard E. Flying cars are just two years away: Terrafugia claims its TF-X will be ready to take to the skies by 2018. MailOnline. 19.February 2016. www.dailymail.co.uk

9. Philip S.Terrafugia TF-X the flying supercar, From Top Gear 30 July 2015. www.bbc.com

10. Renner M. "Vehicle Production Rises, But Few Cars Are "Green" Worldwatch Institute." Worldwatch Institute". 2018. www.tandfonline.com

11. Shivali Best For Mailonline. Flying cars could hit the skies in 2019 after Volvo's parent company. Geely buys 'street-legal plane' startup Terrafugia. 14 November 2017 www.dailymail.co.uk

12. https://moller.com/

13. https://www.italdesign.it/project/popup/

14. https://www.pal-v.com/

15. https://www.aeromobil.com/

16. https://www.auto-motor-i-sport.pl

17. http://www.slashgear.com

18. https://mashable.com

19. https://newatlas.com

20. https://airandspace.si.edu

21. https://www.popularmechanics.com

22. https://www.reddit.com

\section{The flying car}

The article presents the history of the origins of the production of flying cars. The contemporary challenges faced by the constructors of flying aircraft have been described. The companies involved in the design of structures and the production of flying cars have been presented. Some of the ongoing works on design were presented and future strategies for their development were discussed.

Autor:

mgr inż. Bogusława Berner

Politechnika Koszalińska, Wydział Mechaniczny. 